\title{
Micro-pillar compression tests to characterize the mechanical behavior of a nanocrystalline layer induced by SMAT in a $316 \mathrm{~L}$ stainless steel
}

\author{
Z. Sun $^{1}$, D. Retraint ${ }^{1}$, B. Guelorget ${ }^{1}$ and L. Waltz ${ }^{2}$
}

\begin{abstract}
Micro-pillar compression tests were used to study the mechanical behavior of a stainless steel treated by SMAT (Surface Mechanical Attrition Treatment), particularly the induced nanocrystalline surface layer. Micro-pillars were first machined using a Focused Ion Beam (FIB) on the cross-section of the SMATed specimen. They were then deformed with a flat head mounted on a nanoindenter. Stress-strain curves were obtained for various micro-pillars machined at different distances from the SMATed surface. Deformed micro-pillars after compression tests were examined using FEG SEM to analyze deformation mechanisms. According to the obtained stress-strain curves, the mechanical strength of the stainless steel is significantly improved after SMAT, and the deformation mechanisms of the material appear to be different according to the distance from the treated surface.
\end{abstract}

Key words: SMAT / surface nanocrystallization / nanocrystalline material / compression tests / micro-pillars

Résumé - Compression de micro-piliers pour caractériser le comportement mécanique de la couche nanocristalline induite par SMAT dans un acier inoxydable 316L. La technique de compression de micro-piliers a été utilisée pour étudier le comportement mécanique d'un acier inoxydable traité par le procédé SMAT (Surface Mechanical Attrition Treatment), notamment pour la couche superficielle nanocristalline induite. Des micro-piliers usinés par FIB (faisceau d'ions focalisé) ont été déformés en compression à l'aide d'un poinçon plat monté sur un nano-indenteur. Des courbes contrainte-déformation ont pu ainsi être obtenues pour les différents micro-piliers préparés dans des zones à différentes distances par rapport à la surface traitée. Les micro-piliers ont été examinés après compression à l'aide d'un MEB FEG afin d'analyser les mécanismes de déformation mis en jeu. Selon les courbes de compression obtenues, la résistance mécanique est nettement augmentée après SMAT et les mécanismes de déformation mis en jeu semblent différer en fonction de la distance par rapport à la surface traitée.

Mots clés : SMAT / nanocristallisation superficielle / matériau nanocristallin / essais de compression / micro-piliers

\section{Introduction}

Surface treatment processes are very important for many industrial applications in the field of aerospace, automotive or biomedical. Indeed, crack initiation begins very often on the surface of components mechanically loaded in service [1]. The improvement of the surface (mechanical properties and roughness) is an effective way to enhance the overall behavior and increase the lifetime of materials.
SMAT (Surface Mechanical Attrition Treatment) is a technique that can alter the surface layer of coarse grained materials to obtain nano-sized grains by severe plastic deformation (SPD) $[2,3]$. With repetitive mechanical impacts at high strain rate, a large number of defects such as dislocations and consequently grain boundaries may be generated by SMAT, which can progressively lead to nano-sized grains at the surface. Nevertheless, the bulk of the material is not affected by SMAT, and the material characteristics such as grain size remain unchanged

\footnotetext{
1 ICD, LASMIS, University of Technology of Troyes (UTT), UMR 6281, CNRS - Troyes, France

delphine.retraint@utt.fr

2 LMGC, Université Montpellier II, UMR 5508, CNRS - Montpellier, France
} 
Table 1. Chemical composition of the studied steel (in wt\%).

\begin{tabular}{ccccccccccccc}
\hline $\mathrm{Fe}$ & $\mathrm{C}$ & $\mathrm{Mn}$ & $\mathrm{Si}$ & $\mathrm{P}$ & $\mathrm{S}$ & $\mathrm{Cr}$ & $\mathrm{Ni}$ & $\mathrm{Mo}$ & $\mathrm{Cu}$ & $\mathrm{N}$ & $\mathrm{Ti}$ & $\mathrm{V}$ \\
\hline 48.4 & 0.013 & 1.7 & 0.26 & 0.017 & 0.003 & 17.37 & 14.52 & 2.80 & 0.08 & 0.088 & $<0.005$ & 0.07 \\
\hline
\end{tabular}

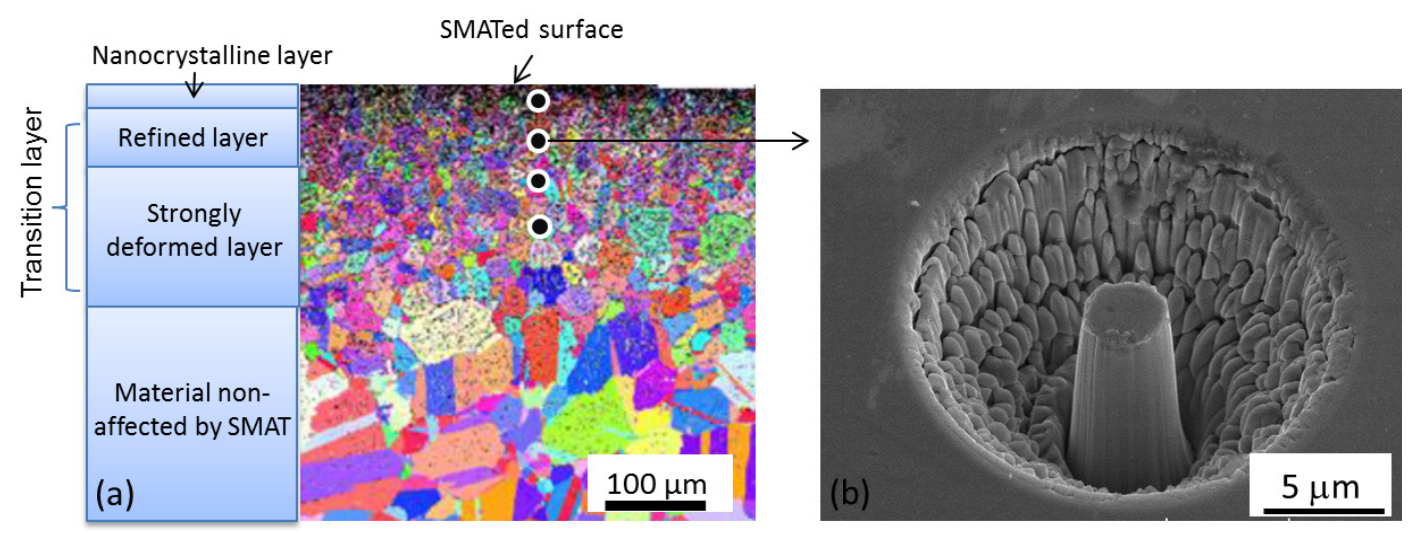

Fig. 1. (a) Cross-section of the SMATed steel: locations of the micro-pillars machined at different distances from the treated surface, (b) example of a micro-pillar prepared by FIB.

Fig. 1. (a) Section transversale de l'acier SMATé : localisation des micro-piliers usinés à différentes distances de la surface traitée, (b) exemple d'un micro-pilier préparé par FIB.

as well as the mechanical properties in this area. Between the nanocrystalline layer and the bulk of the material, a transition layer is present. This transition layer is characterized by a high strain hardening gradient with a grain size which varies from several nanometers (in the nearsurface layer) to several micrometers (in the bulk material). Significant compressive residual stresses can also be present in the region affected by SMAT [4]. These compressive residual stresses coupled with a grain refinement of the microstructure are expected to delay fatigue crack initiation and propagation and thus to enhance fatigue strength of the SMATed alloy [5-7].

In order to understand the gradient of the mechanical behavior of SMATed materials, it is important to characterize the mechanical properties of each layer, for example the nanocrystalline layer and the transition layer. The characterization of the mechanical behavior of the nanocrystalline layer is difficult, given its very small thickness (tens of micrometers). The micro-pillar compression technique was originally used to characterize the mechanical response and to understand the deformation mechanisms of pure Ni single crystals [8], Au [9] and Mo [10]. It is becoming a new approach to quantify the uniaxial mechanical properties of materials at micrometer scale, thus it offers a new way to characterize the mechanical behavior of the nanocrystalline layers.

To our knowledge, the micro-pillar compression technique has not been widely used to study the mechanical behavior of nanocrystalline materials induced by SMAT. This type of mechanical behavior study can be crucial not only in terms of mechanical properties characterization of materials, but also in terms of numerical simulation. Indeed, individual mechanical behavior of each layer needs to be precisely characterized and can then be incor- porated into finite element models to predict the global mechanical response of the SMATed part.

\section{Material and experimental procedures}

In this work, the studied material is a $316 \mathrm{~L}$ stainless steel (AISI 316 - ASTM F138) and the chemical composition of this material is presented in Table 1 . The grain size in the as-received state is between 10 and $50 \mu \mathrm{m}$. SMAT is based on the vibration of spherical shot (3 $\mathrm{mm}$ diameter, in this work) boosted by a high frequency $(20 \mathrm{kHz})$ ultrasonic generator. Random shot impacts are generated at the material surface leading to the formation of multidirectional plastic deformation as well as a superficial nanocrystalline layer. In this paper, the SMAT treatment time is equal to $30 \mathrm{~min}$. A more detailed description of the SMAT process can be found in references $[2,3]$.

After SMAT of the sample surface, the technique of focused ion beam (FIB) was used to "machine" micropillars in the cross-section of the SMATed samples in different regions beneath the treated surface including the nanocrystalline layer (see Fig. 1a). The micro-pillars have a truncated cone shape. The upper and the lower diameter are respectively 2 and $4 \mu \mathrm{m}$, whereas the height is $10 \mu \mathrm{m}$. Figure 1b shows an example of a micro-pillar prepared by FIB in this study.

The compression tests were carried out with a Nanoindenter XP (Nanoinstruments, Knoxville), using a flat circular diamond head with a diameter of $11 \mu \mathrm{m}$. The indenter speed was varied in order to ensure a constant ratio $\dot{h} / h$ equal to $0.05 \mathrm{~s}^{-1}$, with $h$ being the penetration depth. The force-displacement curves were rectified to obtain the stress-strain curves. To do this, the average diameter of 


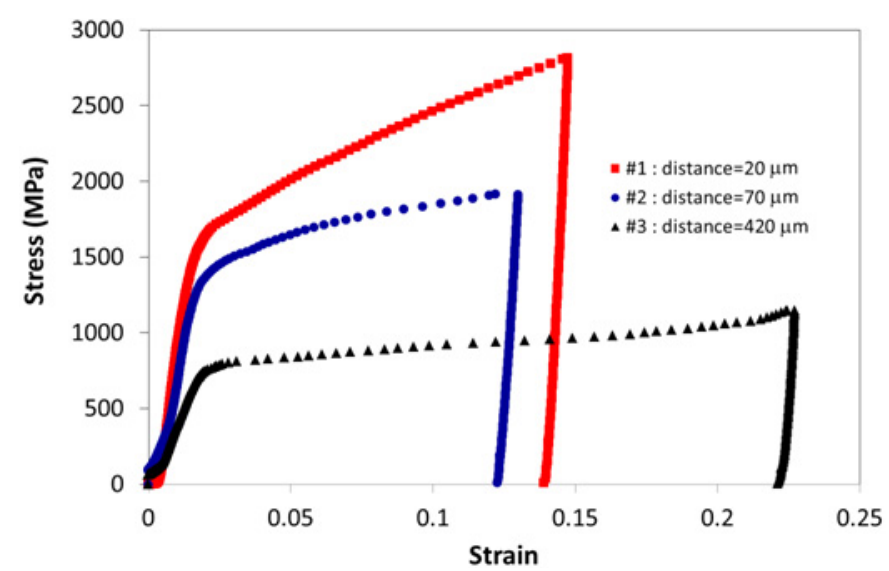

Fig. 2. Nominal stress-strain curves obtained by compression tests of micro-pillars machined at different distances from the SMATed surface.

Fig. 2. Courbes contrainte-déformation nominale obtenues par essais de compression de micro-piliers situés à différentes distances de la surface SMATée.

the micro-pillar was used to calculate the stresses. In addition, the Sneddon criterion [11] was used to calculate the displacement of the upper surface purely due to micropillar deformation. In this criterion, the elastic deformation of the substrate below micro-pillar and that of the diamond indenter were subtracted from the displacement measured by the instrument $[12,13]$. With this criterion, the real displacement of the upper surface of micro-pillar $d_{p}$ is given by the equation as follows:

$d_{p}=d_{\text {meas }}-\frac{\left(1-v_{i}^{2}\right)}{E_{i}}\left(\frac{F_{\text {meas }}}{D_{\text {top }}}\right)-\frac{\left(1-v_{b}^{2}\right)}{E_{b}}\left(\frac{F_{\text {meas }}}{D_{\text {bottom }}}\right)$

where $d_{\text {meas }}$ and $F_{\text {meas }}$ represent the displacement of the micro-pillar surface and the force measured by the nanoindenter respectively. $E_{i}, E_{b}, v_{i}$ and $v_{b}$ are respectively the Young's moduli and Poisson's ratios of the diamond indenter (1141 GPa and 0.07 [14]) and the substrate (base) of the micro-pillars. Finally, $D_{\text {top }}$ and $D_{\text {bottom }}$ represent the upper and the lower diameter of each micropillar respectively.

Knowing the real displacement of the upper surface of micro-pillar, the strain can be calculated by dividing it by the initial length of each micro-pillar.

The deformed state of all micro-pillars after compression was examined with scanning electron microscopy (SEM).

\section{Results and discussion}

Figure 2 shows the nominal stress-strain curves obtained during the compression tests of micro-pillars machined at different distances from the treated surface, including the nanocrystalline layer. It can be seen that for all the stress-strain curves, an initial non-linearity occurs

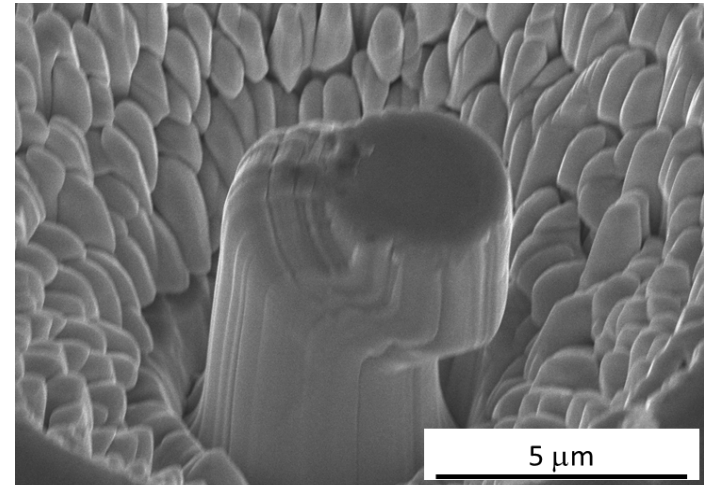

Fig. 3. Example of a deformed micro-pillar located at a distance of $420 \mu \mathrm{m}$ beneath the treated surface (in the SMAT non-affected area), after a compression test $(\varepsilon \sim 0.22)$.

Fig. 3. Exemple d'état déformé d'un micro-pilier situé à une distance de 420 $\mathrm{mm}$ sous la surface traitée (dans la zone non affectée par le SMAT), après un essai de compression $(\varepsilon \sim 0.22)$.

when the head of the diamond indenter begins to get into contact with the upper surface of each micro-pillar, probably because the flat indenter and the micro-pillars are not perfectly parallel. Then, the stress increases linearly with the deformation, which corresponds to the elastic range of the deformation of the material. Then the material enters in the range of plastic deformation.

The micro-pillar strength represented by yield stress is much higher in the nanocrystalline layer which is close to the treated surface. The reached yield stress level for the curve obtained for a micro-pillar located at a distance of $20 \mu \mathrm{m}$ (\#1) beneath the surface is about twice as large as that obtained for a micro-pillar at a distance of $420 \mu \mathrm{m}$ (\#3). It is important to note that the micro-pillar machined in the nanocrystalline layer $(\# 1)$ is composed of nanograins and submicron grains with an average size of about $20 \mathrm{~nm}[6]$.

According to the micro-hardness curves presented in reference [15], the total depth affected by SMAT is about $400 \mu \mathrm{m}$. The micro-pillar \#3 is therefore located in an area that is not affected by SMAT where grains have an initial size between 10 and $50 \mu \mathrm{m}$. Given the small dimension of the micro-pillars compared to the grain size of material, the micro-pillar \#3 is probably composed of a single crystal. This point of view seems to be confirmed by SEM observations of the deformed state of this micropillar (see Fig. 3). For the micro-pillar \#3, slip bands are clearly visible on the surface, which represent the concentration of plastic slip (Fig. 3). This phenomenon is not present for the micro-pillar \#1 which is in the nanocrystalline layer (Fig. 4). This means that micropillars machined in the nanocrystalline layer are more isotropic since they contain a great number of grains as the grain size (nanoscale) is very small compared to the dimension of the micro-pillars. For the stress-strain curve obtained with a micro-pillar located in the transition layer (\#2, with a distance from the SMATed surface equal to $70 \mu \mathrm{m}$ ), the reached stress level is intermediate (Fig. 2). In 


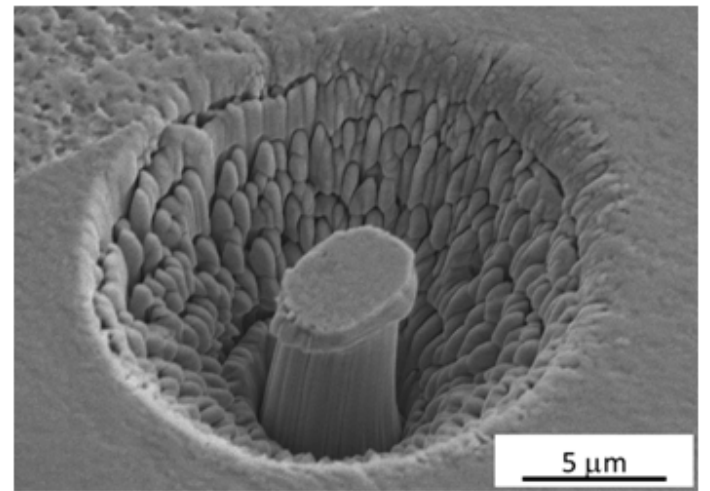

Fig. 4. Example of a deformed micro-pillar machined at a distance of $20 \mu \mathrm{m}$ below the SMATed surface (in the nanocrystalline layer), after a compression test with $\varepsilon \sim 0.15$.

Fig. 4. Exemple d'état déformé d'un micro-pilier situé à une distance de $20 \mu \mathrm{m}$ (dans la couche nanocristalline), après un essai de compression avec $\varepsilon \sim 0.15$.

addition, the plastic slip present on the surface of micropillar is much less remarkable than for the micro-pillar \#3 which is thought to be composed of a single crystal (Fig. 5).

The second element that can be seen on the curves is the strain hardening phenomenon, represented by the slope of the stress-strain curve in the plastic deformation range. First of all, a strong level of strain hardening can be observed for the micro-pillars machined in the nanocrystalline layer. It seems that in the literature, for nano-materials elaborated by different processes such as accumulative rolling and annealing, ECAP (equal-channel angular pressing), the strain hardening capacity is very limited or absent $[16,17]$. However, these elaboration processes are different from SMAT, and to the authors' knowledge, the mechanical behavior of the nanostructured layer induced by SMAT has never been directly characterized. Another possible reason for this strong strain hardening could be due to the fact that the shape of micro-pillars used in this study is not cylindrical but is a truncated cone. Further work is under progress in this way.

According to the curves, qualitatively the strain hardening level is dependent on the areas where the micropillars are machined. It is much greater in the nanocrystalline layer $(\# 1)$ than in the regions where the grain size is in the micrometer scale (\#3) (Fig. 2). This means that the deformation mechanisms may be different according to the location where the micro-pillars are machined and more precisely to the distance from the treated surface. In a single crystal, the deformation is essentially accommodated by plastic slip, while in the case of a material with nanograins, the deformation mechanism can be fundamentally different. Indeed, when the grain size is reduced to ultrafine and/or nanocrystalline regime, there is a significant effect of grain size on the mechanical behavior and the mode of microscopic deformation. For example, when the grain size decreases to nanometer scale, the

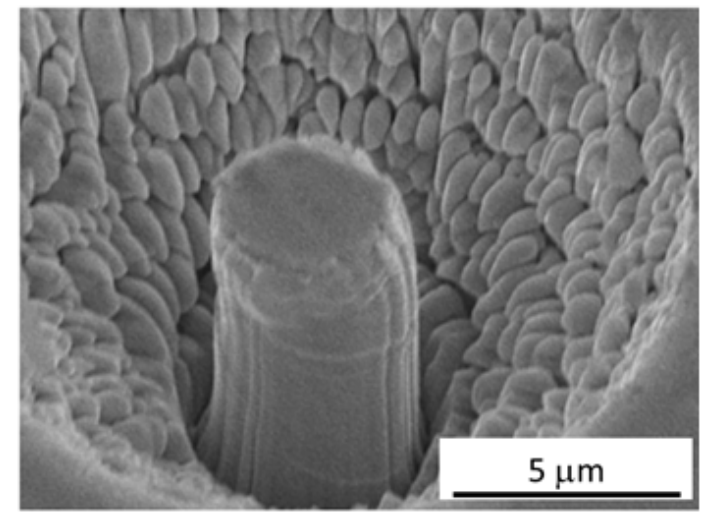

Fig. 5. Example of a deformed micro-pillar located at a distance of $70 \mu \mathrm{m}$ beneath the SMATed surface (in the transition area), after a compression test of $\varepsilon \sim 0.13$.

Fig. 5. Exemple de l'état déformé d'un micro-pilier situé à une distance de $70 \mu \mathrm{m}$ sous la surface traitée (dans la zone de transition), après un essai de compression avec $\varepsilon \sim 0.13$.

grain boundary sliding and / or rotation of the grains tend to be dominant [18]. As for the transition layer, the strain hardening phenomenon is intermediate. In this zone, the material is mechanically reinforced by strain hardening and a high dislocation density is expected to be present, which makes the strain hardening effect higher than in a non-hardened material (in the SMAT non affected area, for example see micro-pillar \#3).

\section{Conclusions}

The micro-pillar compression technique was used to study the mechanical behavior of a $316 \mathrm{~L}$ stainless steel treated by SMAT. The following conclusions can be obtained:

- The strength of material represented by yield stress is significantly enhanced by the nanocrystallization phenomenon induced by SMAT.

- Deformation mechanisms are different according to the location of the micro-pillars beneath the SMATed surface.

As an outlook, several elements could be considered and studied in more details. In terms of experimental tests, the reproducibility will be studied by performing compression tests in other zones with the same distances to the SMATed surface. In addition, the effect of micro-pillars size will be studied to see the effect of this parameter on the stress-strain curves as a function of the grain size gradient. In terms of numerical simulations, the mechanical properties of each layer can be incorporated into finite element models to predict the global mechanical behavior of materials processed by SMAT.

Acknowledgements. Financial support for this research from the Champagne-Ardenne Research Council through Nanosurf and Nanotribo projects is greatly appreciated. This work was 
also partly supported by the French RENATECH network and the authors acknowledge the scientific and technical assistance of D. Troadec.

\section{References}

[1] T.M. Abdel-Fattah, D. Loftis, A. Mahapatro, J. Biomed. Nanotechnol. 7 (2011) 794-800

[2] K. Lu, J. Lu, J. Mater. Sci. Technol. 15 (1999) 193-197

[3] K. Lu, J. Lu, Mater. Sci. Eng. A 375-377 (2004) 38-45

[4] T. Roland, D. Retraint, K. Lu, J. Lu, Mater. Sci. Forum 490-491 (2005) 625-630

[5] J. Uusitalo, L.P. Karjalainen, D. Retraint, M. Palosaari, Mater. Sci. Forum 604-605 (2009) 239-248.

[6] T. Roland, D. Retraint, K. Lu, J. Lu, Scr. Mater. 54 (2006) 1949-1954

[7] D. Retraint, Matériaux \&J Techniques 99 (2011) 101-104

[8] M.D. Uchic, D.M. Dimiduk, J.N. Florando, W.D. Nix, Science 305 (2004) 986-989
[9] J.R. Greer, W.C. Oliver, W.D. Nix, Acta Mater. 53 (2005) 1821-1830

[10] J.Y. Kim, D.C. Jang, J.R. Greer, Acta Mater. 58 (2010) 2355-2363

[11] I.N. Sneddon, Int. J. Eng. Sci. 3 (1965) 47-57

[12] C.P. Frick, B.G. Clark, S. Orso, A.S. Schneider, E. Arzt, Mater. Sci. Eng. A 489 (2008) 319-329

[13] H. Fei, A. Abraham, N. Chawla, H. Jiang, J. Appl. Mech. 79 (2012) 061011

[14] G. Simmons, H. Wang, Single crystal elastic constants and calculated aggregate properties, A handbook, MIT Press, Cambridge MA, 1971

[15] Z. Sun, M. Chemkhi, P. Kanoute, D. Retraint, IOP Conf. Ser.: Mater. Sci. Eng. 63 (2014) 012021

[16] Y.F. Shen, X.M. Zhao, X. Sun, Y.D. Wang, L. Zuo, Scr. Mater. 2015, In press

[17] M.A. Meyeres, A. Mishra, D.J. Benson, Prog. Mater. Sci. 51 (2006) 427-556

[18] K.T. Ramesh, Nanomaterials - Mechanics and Mechanisms, Springer, 2009 